\title{
Prognostic Effect of Stromal Myofibroblasts in Lung Adenocarcinoma
}

\author{
H. SHU ${ }^{1, *}$, H. F. $\mathrm{LI}^{2}$ \\ ${ }^{1}$ Department of pathology, Shengjing Hospital of China Medical University, Shenyang Liaoning, 110004, P.R. China; ${ }^{2}$ Department of pathology, \\ The Second Affiliated Hospital of Nanjing Medical University, Nanjing, Jiangsu, 210011,P.R. China \\ ${ }^{*}$ Correspondence: shuhong0302@hotmail.com
}

Received April 16, 2012 / Accepted May 21, 2012

\begin{abstract}
Myofibroblasts are special cells with the features of both fibroblasts and smooth muscle cells, which are one of the most important cells in tumor stroma. The role of myofibroblasts in tumor stroma remains disputable. Some authors suggested that myofibroblasts can facilitate tumor progress, and another considered that myofibroblasts could prevent tumor cells diffusing. Bronchioloalveolar carcinoma (BAC) is a kind of adenocarcinoma in situ. With the destruction of the alveolar framework by tumor growth, $\mathrm{BAC}$ develops into mixed $\mathrm{BAC}$ and invasive adenocarcinoma, which is a natural model of transformation from carcinoma in situ to invasive carcinoma. In this study, the expression of myofibroblasts in BAC, mix-BAC and invasive adenocarcinoma was examined by immunohistochemical staining of surgical specimens from 102 patients. The results showed that positive expression of myofibroblasts in pure BAC (2/15, 13.33\%) group was lower than in mix-BAC $(17 / 38,44.74 \%)$ and invasive adenocarcinoma $(29 / 49,59.18 \%)$ respectively, $(\mathrm{p}<0.05, \mathrm{p}<0.01)$. In addition, myofibroblast positive expression was associated with lymph node metastasis, high stage, high grade, vascular invasion and shortened survival time in patients with lung adenocarcinoma. These data suggest that myofibroblasts are likely to facilitate the invasion and metastasis of the lung adenocarcinoma, and can be used as a prognostic marker. Myofibroblasts may become even a new target for treatment.
\end{abstract}

Key words: lung adenocarcinoma, myofibroblast, immunohistochemistry, prognosis

In China, the incidence of the lung cancer is the first in city, and the forth in countryside. Usually, most of patients with lung cancer had been lost the opportunity of surgery because they were in advanced stage when they went to a hospital, and many postsurgery patients had poor prognosis because of the distant metastasis.

Myofibroblasts are special cells with the features of both fibroblasts and smooth muscle cells, which are one of the most important cells in tumor stroma.

Myofibroblasts are classified into four subtype on the basis of their cytoskeletal elements [5] — the presence and/or absence of microfilaments ( $\alpha$-SMA, A) and intermediate filaments (desmin $\mathrm{D}$ and vimentin $\mathrm{V}$ ): V, VD, VA, and VAD.

Myofibroblasts in tumor stroma were also called carcinoma associated fibroblasts. Many findings suggested that most myofibroblasts come from fibroblasts [1], some came from bone marrow-derived cells [2] and epithelial-mesenchymal transition cells [3] and others. They can express many cytokines, protease and adhesion molecules. There is increasing evidence to suggest that myofibroblasts play an important role during tumor progress $[4,5]$. Previous studies tended to suggest that the myofibroblasts are protective cells to prevent the growth and migration of tumor cells. Currently, more and more studies suggested that myofibroblasts in tumor have close association with tumor cells invasion.

In order to study the role of myofibroblasts in lung adenocarcinoma, we carried out a clinicopathological study on the relationship between the myofibroblasts and tumor. This can provide more evidence for the mechanism of invasion and metastasis of lung adenocarcinoma.

\section{Patients and methods}

Patients. 102 patients with primary lung adenocarcinoma, which tumor size was less than or equal to $3 \mathrm{~cm}$ in maximum diameter, from 2003 through 2007 were selected from the database of the Shengjing Hospital of China Medical University. The patients consisted of 43 men and 59 women. Median age was 57 years old (range, 29-85). None of them had preoperative chemotherapy or radiotherapy. Based on the TNM stage system, 44 patients were in staged I, 18 in II, 37 in III and 3 in IV. According to the WHO classification, the tumors were clas- 
sified into pure Bronchioloalveolar carcinoma (BAC), mixed $\mathrm{BAC}$ (BAC is the main component of the tumor) and other invasive adenocarcinoma (non-BAC). Of them, 67 patients had clinical follow-up. The followed-up period was 32 months to 78 months. 40 patients were alive and 27 died.

The tumors were fixed in $10 \%$ neutral formalin and were embedded in paraffin. All sections were stained with Hematoxylin-eosin, Masson and immunohistochemical staining.

Masson's Trichrome staining. After deparaffinized and dehydrated, the sections were immersed into hematoxylin for 30 seconds followed by iron alum sulfate solution for $15 \mathrm{~min}$. Then they were put in ponceau $\mathrm{S}$ solution, $1 \%$ phosphomolybdic acid solution and $2 \%$ aniline blue solution at room temperature respectively. After dehydrated and clear, the sections were mount.

Immunohistochemistry. Immunohistochemistry was performed using a PV9000 IHC kit (Zhongshan Biological Inc., Beijing, China). Tissue sections (5- $\mu \mathrm{m})$ were deparaffinized in xylene and dehydrated in ethanol. Antigen recovery was processed with microwave. Sections were blocked by pretreatment with $3 \% \mathrm{H}_{2} \mathrm{O}_{2}$ for $10 \mathrm{~min}$ at room temperature and incubated respectively with primary antibodies against SMA, desmin, Vimentin and CD34 (Zhongshan Biological Inc., Beijing, China.) for 2 hour at room temperature. After the sections were incubated with reagent 1 and reagent 2 for $30 \mathrm{~min}$ at room temperature respectively, $\mathrm{DAB}$ was used to visualize the antigen.

Interpretation of results. Stromal immunostaining for SMA or desmin was assessed as "+" and "-". The "+" was defined as positive immunostaining in $>10 \%$ stromal staining. The "-" was defined as positve immunostaining in $\leq 10 \%$.

Masson's Trichrome Method can make the collagen protein blue, smooth muscle red and cellular nucleus brown. When tumor cells invaded the stroma, the continuity of collagen or smooth muscle would be destructed.

Statistics. All analyses were done using SPSS statistical software version 18.0. Statistical evaluation of correlations was carried out using t-test. The survival curves were constructed using Kaplan-Meier method. Statistical differences were considered to be significant for $\mathrm{P}<0.05$.

\section{Results}

Myofibroblasts phenotype. The myofibroblasts in all 102 cases of lung adenocarcinoma were positive for Vimentin and a-SMA (Fig.1a), not for desmin, The subtype of myofibroblasts in our study was VA.

Correlation with clinicopathologic variables. In patients with lymph nodes metastasis myofibroblasts expression was revealed in 29 from 50 cases (58.00\%), and without lymph node metastasis in 19 from 52 (36.54\%). The difference was significant $(\mathrm{p}<0.05)$. In stage I and II myofibroblasts expression was positive in 23 from 62 (37.10\%), in stage III and IV in 25 from $40(62.50 \%)$, and this difference was significant $(\mathrm{p}<0.05)$. The positive expression of myofibroblasts in pure BAC $(2 / 15$, $13.33 \%)$ group was lower than in mix-BAC (17/38, 44.74\%)
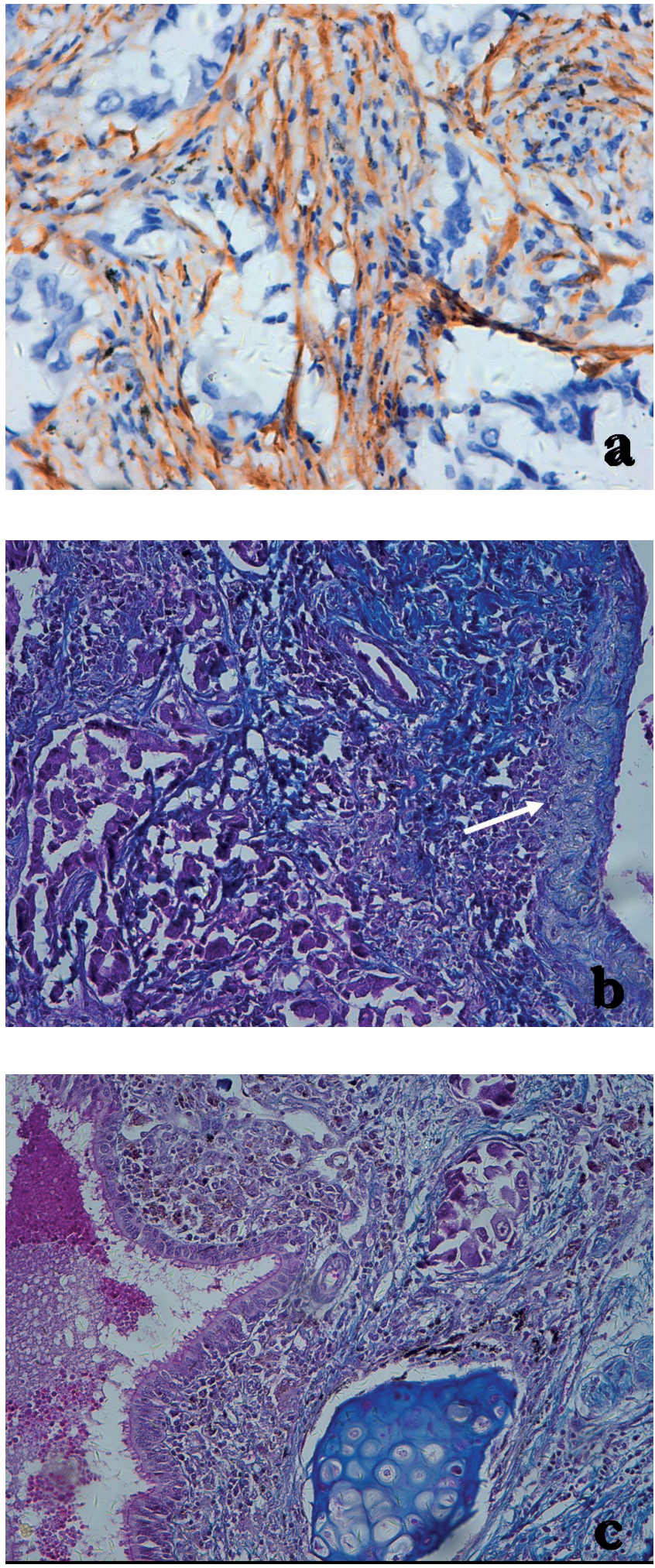

Figure 1. a) Myofibroblasts were positive for SMA in lung adenocarcinoma by immunohistochemistry. $(\times 400)$

b) Perivascular connective tissue was invaded by tumor cells (arrow showed the vascular wall, Masson stain $\times 400$ ).

c) Bronchial wall was invaded by tumor cells (Masson stain $\times 400$ ). 


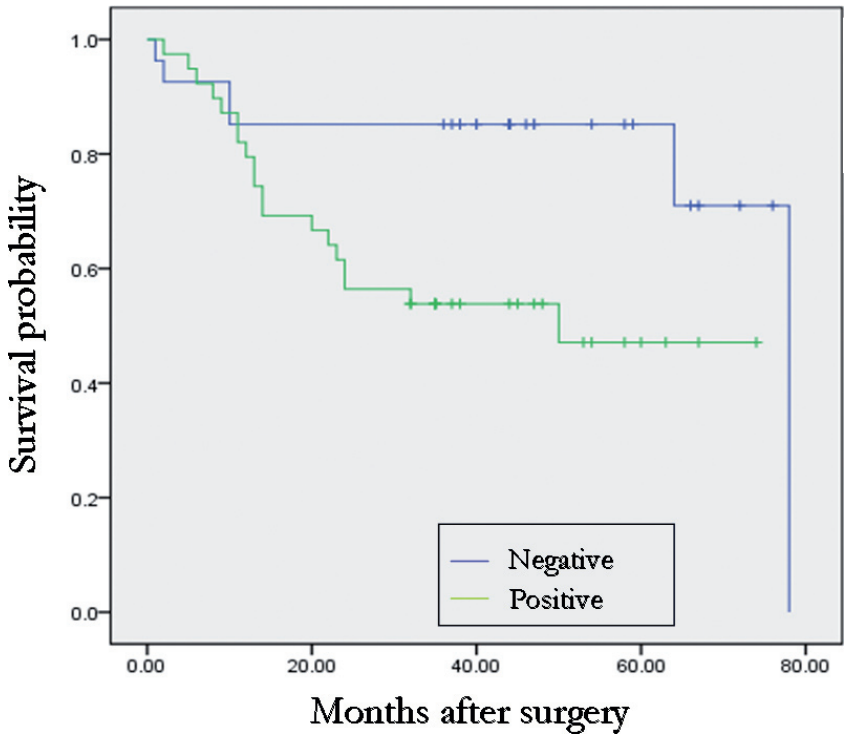

Figure 2. Kaplan-Meier survival curves of patients with myofibroblasts positive or negative $(\mathrm{P}=\mathbf{0 . 0 1 5})$.

and non-BAC $(29 / 49,59.18 \%)$ respectively, $(\mathrm{p}<0.05, \mathrm{p}<0.01)$. No correlation was found for gender, age and smoking history (Table 1).

Table 1. Associations of expression of myofibroblasts of lung carcinoma with clinicopathologic variables

\begin{tabular}{|c|c|c|c|c|c|}
\hline \multirow[b]{2}{*}{ Factors } & \multirow[b]{2}{*}{$\mathrm{n}$} & \multicolumn{2}{|c|}{ myofibroblast } & \multirow[b]{2}{*}{$\mathrm{X}^{2}$} & \multirow[b]{2}{*}{$\mathrm{P}$} \\
\hline & & $(-)$ & $(+)$ & & \\
\hline \multicolumn{6}{|l|}{ Gender } \\
\hline Male & 43 & 23 & 20 & & \\
\hline Female & 59 & 31 & 28 & 0.090 & 0.925 \\
\hline \multicolumn{6}{|l|}{ Age (year) } \\
\hline$\leq 55$ & 41 & 23 & 18 & & \\
\hline$>55$ & 61 & 31 & 30 & 0.274 & 0.601 \\
\hline \multicolumn{6}{|c|}{ smoking history } \\
\hline Positive & 38 & 21 & 17 & & \\
\hline Negative & 64 & 33 & 31 & 0.131 & 0.717 \\
\hline \multicolumn{6}{|l|}{ Histotype } \\
\hline BAC & 15 & 13 & 2 & $4.612 \#$ & 0.032 \\
\hline mix-BAC & 38 & 21 & 17 & $9.667^{*}$ & 0.002 \\
\hline non-BAC & 49 & 20 & 29 & 1.793 放 & 0.181 \\
\hline \multicolumn{6}{|c|}{ Lymph node metastases } \\
\hline Negative & 52 & 33 & 19 & & \\
\hline Positive & 50 & 21 & 29 & 4.713 & 0.030 \\
\hline \multicolumn{6}{|l|}{ TNM stage } \\
\hline I-II & 62 & 39 & 23 & & \\
\hline III-IV & 40 & 15 & 25 & 6.298 & 0.012 \\
\hline
\end{tabular}

\# BAC group VS mix-BAC group; ${ }^{*}$ BAC group VS non-BAC group; ‘ $\lesssim$ mix-BAC group VS non-BAC group.

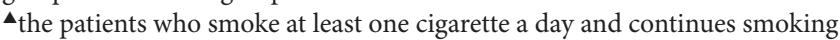
more than a year.
Correlation with invasion. The associations between expression of myofibroblasts and stromal invasion are showed in Table 2. In patients with vascular invasion (including perivascular connective tissue and vessel wall involvement, Fig.1b) myofibroblasts expression was positive in 37 from 66 cases $(56.06 \%)$, and without vascular invasion in 11 from 36 $(30.56 \%)$. This difference was significant $(\mathrm{p}<0.05)$. Myofibroblasts expression was revealed in 23 from $51(45.10 \%)$ in patients with bronchial invasion (including peribrochial connective tissue and bronchial wall involvement, Fig.1c), and without bronchial invasion in 25 from 51 (49.02\%), and no statistical difference was observed $(\mathrm{P}>0.05)$.

Kaplan-Meier analysis. The Kaplan-Meier survival curves (Fig.2) for expression of myofibroblasts revealed close correlation with overall survival $(\operatorname{logrank}=5.885, \mathrm{p}=0.015)$. The average survival time of patients with myofibroblasts negative tumors (65.309 \pm 5.611 months) was significantly longer than myofibroblasts positive tumors(44.974 \pm 4.822 months).

\section{Discussion}

The role of myofibroblasts in tumor stroma remains disputable. Granot D et al. $[7,8]$ showed that myofibroblasts produced a multitude of enzymes that could degrade the extracellular matrix and basemembrane, which contributed to the invasion of tumor cells. Kawashiri $S$ et al [9]. showed that squamous cell carcinoma of oral cavity with higher expression of myofibroblasts had poor prognosis. Orimo A et al. [10] thought that myofibroblasts were shown to stimulate invasive growth of breast cancer cells. On the other hand, Caporale et al. $[11,12]$ considered that desmoplastic reaction was a protective factor for survival in patients with colorectal carcinoma. Vivien J et al. [13] showed that colorectal cancer desmoplastic reaction up-regulated collagen synthesis and restricted cancer cell invasion.

In this paper, myofibroblast positive expression was associated with lymph node metastasis, high stage and high grade of lung adenocarcinoma, which showed myofibroblasts promote tumor progression.

BAC is a kind of adenocarcinoma in situ, in which the alveolar framework is integrated. With the destruction of the alveolar framework by tumor growth, that is, stromal

Table 2. Associations of expression of myofibroblast with invasion of lung carcinoma

\begin{tabular}{llllll}
\hline & & \multicolumn{2}{c}{ myofibroblast } & & \\
\cline { 3 - 4 } & $\mathrm{n}$ & $(-)$ & $(+)$ & $\mathrm{X} 2$ & $\mathrm{P}$ \\
\hline Branchial invasion & & & & & \\
$\quad$ Negative & 51 & 26 & 25 & & \\
$\quad \begin{array}{l}\text { Positive } \\
\text { Vascular invasion }\end{array}$ & 51 & 28 & 23 & 0.157 & 0.692 \\
$\quad$ & & & & & \\
$\quad$ Negative & 36 & 25 & 11 & & \\
$\quad$ Positive & 66 & 29 & 37 & 6.082 & 0.014 \\
\hline
\end{tabular}


invasion, BAC develops into mixed BAC and non-BAC adenocarcinoma, which is a natural model of transformation from carcinoma in situ to invasive carcinoma. In our study, the positive expression of myofibroblasts in pure $\mathrm{BAC}$ group was lower than in mix-BAC and non-BAC respectively, which showed that myofibroblasts played an important role from pure BAC to invasive adenocarcinoma.

A strong relationship was observed between the positive expression of myofibroblasts and the vascular invasion, which revealed that myofibroblasts could promote tumor cells to invade blood vessels and contribute tumor metastasis. But no relationship was found between myofibroblasts positive expression and bronchial invasion. The possible reason is that the myofibroblasts in tumor can secret some kinds of vascular chemotactic factors, which can make the tumor cells invade blood vessels easily.

Kaplan-Meier survival curves showed a significant association between increased myofibroblasts and a shortened survival time in patients.

These data suggest that myofibroblasts were associated with the invasion and metastasis of the lung adenocarcinoma, and can be used as a prognostic marker. Myofibroblasts may become even a new target for treatment.

\section{References}

[1] SINGH S, SADANANDAM A, SINGH RK. Chemokines in tumor angiogenesis and metastasis. Cancer Metastasis Rev 2007; 26: 453-467. http: //dx.doi.org/10.1007/s10555-007$\underline{9068-9}$

[2] BHOWMICK N A, NEILSON E G, MOSES H L. Stromal fibroblasts in cancer initiation and progression. Nature 2004; 432(7015): 332-337. http: //dx.doi.org/10.1038/nature03096

[3] HINO M, DOIHARA H, KOBAYASHI K, AOE M, SHIMIZU N. Caveolin-1 as tumor suppressor gene in breast cancer. Surg Today 2003; 33(7): 486-490.

[4] CHARALABOPOULOS K, GOGALI A, KOSTOULA OK, CONSTANTOPOULOS SH. Cadherin superfamily of adhesion molecules in primary lung cancer. Exp Oncol, 2004, 26: 256-260.

[5] DE WEVER O, DEMETTER P, MAREEL M, BRACKE M. Stromal myofibroblasts are drivers of invasive cancer growth.
Int J Cancer 2008;123: 2229-2238. http://dx.doi.org/10.1002/ ijc. 23925

[6] DESMOULIERE A, GUYOT C, GABBIANI G. The stroma reaction myofibroblast: a key player in the control of tumor cell behavior. Int J Dev Biol 2004;48: 509-517. http: //dx.doi. org/10.1387/ijdb.041802ad

[7] GRANOT D, ADDADI Y, KALCHENKO V, HARMELIN A, KUNZ-SCHUGHART LA, et al. In vivo imaging of the systemic recruitment of fibroblasts to the angiogenicrim of ovarian carcinoma tumors. Cancer Res 2007;67: 9180-9189. http: //dx.doi.org/10.1158/0008-5472.CAN-07-0684

[8] GAGGIOLI C, HOOPER S, HIDALGO-CARCEDO C, GROSSE R, MARSHALL JF, et al. Fibroblast-led collective invasion of carcinoma cells with differing roles for Rho-GTPases in leading and following cells. Nat Cell Biol 2007; 9: 1392-1400. http: //dx.doi.org/10.1038/ncb1658

[9] KAWASHIRI S, TANAKA A, NOGUCHI N, HASE T, NAKAYA H, et al. Significance of stromal desmoplasia and myofibroblast appearance at the invasive front in squamous cell carcinoma of the oral cavity. Head Neck 2009; 31: 13461353. http: //dx.doi.org/10.1002/hed.21097

[10] ORIMO A, GUPTA PB, SGROI DC, ARENZANA-SEISDEDOS F, DELAUNAY T, et al. Stromal fibroblasts present in invasive human breast carcinomas promote tumor growth and angiogenesis through elevated SDF-1/CXCL12 secretion. Cell 2005;121:335-348. http://dx.doi.org/10.1016/ j.cell.2005.02.034

[11] CAPORALE A, VESTRI AR, BENVENUTO E, MARIOTTI $\mathrm{M}$, COSENZA UM, et al. Is desmoplasia a protective factor for survival in patients with colorectal carcinoma? Clin Gastroenterol Hepatol 2005;3: 370-375. http: //dx.doi. org/10.1016/S1542-3565(04)00674-3

[12] CAPORALE A, AMORE BONAPASTA S, SCARPINI M, CIARDI A, VESTRI A, et al. Quantitative investigation of desmoplasia as a prognostic indicator in colorectal cancer. J Invest Surg 2010; 23: 105-109. http: //dx.doi.org/10.3109/ $\underline{08941930903469417}$

[13] COULSON-THOMAS VJ, COULSON-THOMAS YM, GESTEIRA TF, DE PAULA CA, MADER AM, et al. Colorectal cancer desmoplastic reaction up-regulates collagen synthesis and restricts cancer cell invasion. Cell and Tissue Research 2011; 346: 223-236. http: //dx.doi.org/10.1007/s00441-011$\underline{1254-\mathrm{y}}$ 